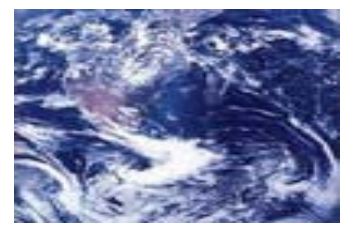

\title{
Elements of Effective e-Learning Design
}

\author{
Andrew R. Brown \\ Queensland University of Technology \\ Brisbane, Australia
}

Bradley D. Voltz

St Joseph's Nudgee College

Brisbane, Australia

\begin{abstract}
Preparing and developing e-learning materials is a costly and time consuming enterprise. This paper highlights the elements of effective design that we consider assist in the development of high quality materials in a cost efficient way. We introduce six elements of design and discuss each in some detail. These elements focus on paying attention to the provision of a rich learning activity, situating this activity within an interesting story line, providing meaningful opportunities for student reflection and third party criticism, considering appropriate technologies for delivery, ensuring that the design is suitable for the context in which it will be used, and bearing in mind the personal, social, and environmental impact of the designed activities. Along the way, we describe how these design elements can be effectively utilized by contextualizing them with examples from an e-learning initiative.
\end{abstract}

Keywords: e-learning; educational design; learning resource development

\section{Introduction}

Educational materials that have been effectively designed will facilitate the achievement of desired learning outcomes for students. Effective design of electronic learning materials relies on instructional design processes that reflect the absence of or reduction in face-to-face instruction. This change in learning context is an important factor distinguishing online or e-learning from traditional instruction, and therefore requires different educational design considerations such as those outlined in this paper. The effects on student learning of changing from traditional to elearning contexts have been widely researched, and a qualitative summary of these findings has been presented by Shakar and Neumann (2003), who conclude that e-learning programs can, but do not always, deliver improved learning outcomes. Young (2003) describes this emerging elearning environment as one that is "adapted and developed for intellectual partnerships" (n.p.), 
suggesting that rich learning activities allow students to learn with computers rather than from computers. The change in learning context affects the student-teacher relationship, which becomes a multifaceted interaction among student, online materials, the broader community of Internet users, and, in many cases, teachers as facilitators and mentors. The unpredictability of the student context and the mediated relationship with the student require careful attention by the educational designer to details which might otherwise be managed by the teacher at the time of instruction. We hope that the elements presented here will assist in clarifying the significant aspects of e-learning design and enable a design process that takes account of considerations traditionally deferred where face-to-face delivery is assumed.

For the purpose of this discussion, we define 'e-learning' as teaching and learning that are delivered, supported, and enhanced through the use of digital technologies and media. We consider that e-learning may encompass face-to-face, distance, and mixed mode or blended delivery models. The six design elements introduced in this paper provide a framework within which designers of e-learning materials can create online resources, appropriate for $\mathrm{K}-12$ and tertiary settings.

In this paper, we are concerned with the design phase of the e-learning resources. By 'design' we mean the planning or working out of the e-learning resource. This combines tasks including lesson planning, instructional design, creative writing, and software specification. Our design considerations take into account the constraints of building and delivery, but do not assume any particular software methodology or development platform. We acknowledge other variables that may affect design: for example, the use of courseware for delivery. While the use of this kind of software may limit flexibility in designing learning activities, it is nevertheless still important to consider activity at the design stage. Our particular concern is the creation of engaging and appropriate learning experiences that are likely to be utilized and to achieve the intended learning outcomes.

\section{Background}

There is much deliberation in the literature concerning instructional methodology and design. Discussion ranges from considerations of media options and technological hurdles (Bersin, 2003) to attempts to distinguish between online and traditional class materials (Nash, 2004). Existing pedagogical research is limited, according to Frydenberg (2002), who suggests that this is because few fully developed programs have arrived at a stage where summative evaluation is possible. Studies concern mainly the application of traditional teaching concepts to e-learning environments. For example, Roslin Brennan (2003) cites communication, interactivity, and social cohesion as key pedagogical goals, while George Siemens (2003) contends that variety is a central requirement for learning, and that media choices should be made according to desired learning outcomes. Many of these concepts can be traced back to the work of John Dewey (1970), who, in writing about experiential learning, argued that education must engage with and enlarge experience, and that interaction and environments for learning provide a continuing framework for teaching practice. "This process of making meaningful connections is at the core of all learning” (Horton, 2000, p. x; emphasis in original). E-learning materials often reflect these 
concepts through the use of simulations and a focus on interactive learning activities. Jasinski (2001) explores improvization as a strategy to make online materials more meaningful to learners by providing a better balance between content and process. Jasinski contends that this strategy enables a fast transition from the conceptual to the operational, and that students "learn by playing with rules, not by rules, or to create new rules” (n.p.).

A feature of online instruction over paper-based distance learning processes is the ability to employ multiple media types to present ideas and concepts. "Online courses are much more than the posting of traditional in class materials on the Web” (Nash, 2004, n.p.). Text, images, and sound can be combined to create materials that cater for several learning styles, and allow a degree of interactivity on the part of the student. "In the modern world, language is not the only important communicational system. Today images, symbols, graphs, diagrams, artefacts, and many other visual symbols are particularly significant” (Gee, 2003, p. 13). In many cases, the constructivist ideal of online learning matches poorly against the reality of delivery (Brennan, 2003). We believe that paying attention to the core elements of e-learning design outlined here can reduce the gap between educational intention and the reality of student experience.

In this paper, we use as examples the work of The Le@rning Federation (TLF). The TLF is an initiative of state and federal governments of Australia and New Zealand. Over the period 20012006, the initiative aims to develop online interactive curriculum content specifically for Australian and New Zealand schools. References to the work of the TLF have been drawn from our observations of their design and review activities. Our comments are based on data drawn from specification documents, design workshops, conversations with writers and developers, teacher feedback, and the review of draft and final online resources. We elaborate on each of the six elements of effective design, and illustrate these with selected examples.

\section{Design Elements}

In this section, we present six elements at the heart of effective e-learning design, in an attempt to draw attention to the important considerations within a complex system. The design of e-learning resources requires understandings in education, multimedia content, resource publication, and electronic technologies. The sophistication of the task is highlighted by the fact that teams, rather than individuals, are often employed to undertake it. The six areas - activity, scenario, feedback, delivery, context, and impact - cover issues across all disciplines involved in e-learning design, but particularly focus on learning as the driving motivation. In many business situations, the elearning goal is to improve business outcomes. We make the assumption that this is achieved indirectly by the effectiveness of the e-learning training or education, and thus focus on improving that effectiveness.

\section{Activity}

As with other educational design, creating effective e-learning relies on having tasks for students to undertake that provide an experience likely to lead them to the desired new understanding. Despite the apparent obviousness of this requirement, it seems all too easy for providers of e- 
learning to become carried away with, or distracted by, other design elements and to overlook the necessity of providing a rich learning activity. A rich activity is one that opens up opportunities for action rather than directs students down a prescribed pathway. Such an activity "implies the active involvement of the learner in making choices about what experiences to undertake" (Muirhead and Haughey, 2003, p. 15), and is complex enough both to engage and to challenge students for the duration of the study, if not longer. This highlights the view that "the more ways in which the learner is involved in task related activity, the stronger the learning” (Biggs, 1991, p. 219). Learning takes place in the student's mind and body; therefore the activity needs to be considered from the perspective of the actions and challenges it affords the student, rather than the complexity of the materials or tools provided for the activity to take place. As Gee (2003) suggests, an active learning experience is one where students "experience the world in new ways, form new affiliations, and prepare for future learning” (p. 23).

Sonic Space City is a TLF online learning resource that allows students to manipulate and combine sounds typically found in a busy city to produce a soundscape. Trial feedback on this learning object indicates that learner discussion was successfully focused on the timbral choice and temporal structure of the soundscapes, as anticipated by the design. This successful outcome was a result of a design that removed unnecessary distractions from the activity, thus making the task clear, while providing an open ended activity that allowed extensive exploration of the desired creative task. In a review of another TLF resource, Where Do Frogs Lay Their Eggs? it was found that, although the explorative intention of the activity was clear, "it is unclear how the learner locates and identifies the eight different egg laying locations" (Muirhead and Haughey, 2003, p. 31). These examples highlight the fact that the use of an appropriate and clearly evident activity is fundamental to an effective learning outcome, and ensuring that the integrity of the activity is maintained as focus shifts to the media-focused development stages is an ongoing challenge for the e-learning designer.

\section{Scenario}

There needs to be a reason or motivation to undertake an educational activity if the learning is to be memorable and considered valuable. An interesting context or scenario can assist the activity to have meaning. In some situations, the context will either be evident or require little explanation, for example, in relevant workplace training situations or in situations where student motivation is known to be high. In other contexts, possibly the majority, where the learning agenda is largely institutional, students are encouraged and assisted by an interesting scenario into which the activities are placed. Scenarios are usually provided by a story, role play, or simulation, within which the activity plays a pivotal role in helping students to contextualize content (Brodsky, 2003). The scenario will most likely be fictional; however, there is an assumption that the learning or skill gained through the activity will be transferred to future real world situations. This transfer is assisted if the learning scenario raises issues and problems similar to those in the real world; scenarios with this real world correspondence are often referred to as being 'authentic.' An interesting scenario will make extensive use of humor, imagination, reward, anticipation, or drama to enhance the activity. It will have topics and themes likely to be relevant and interesting to the target audience. It will make the learning activity seem like an obvious or 
necessary thing to undertake, given the situation presented by the scenario. Designers of entertainment products have long understood this requirement, and the study of their techniques is of increasing interest to educators such as Gee. In his book What Video Games Have to Teach Us About Learning and Literacy, Gee (2003) suggests that "learners participate in extended engagement (lots of effort and practice) . . . in relation to a virtual world that they find compelling” (p. 67). For the effective design of e-learning materials, the target audience must be clearly identified in order to develop scenarios that are likely to engage and stimulate the learning.

At one TLF workshop that we observed, teachers commented on a number of potential online resources. One of these, entitled Goldfish Bowl, which simulated the maintenance of an aquarium, was well received by teachers. This resource features an authentic scenario, and engages students in the task of setting up and maintaining the tank with the fish of their choice. Another learning object discussed was Bunyip Transit. Its scenario involves a portal that allows a range of otherworldly Australian-based creatures the chance to enter the outside world and subsequently return. Students' problem solving task is to work out the best way to save the creatures by transporting them to the portal. Comments about this activity were that it was fun and that students would like it, but teachers felt that they would have trouble springboarding from it into other activities. They suggested that if a resource is too much like a game with rules unrelated to real world contexts, then teachers would avoid using it. From this feedback, it is clear that authenticity and interest are highly valued aspects of e-learning design scenarios.

\section{Feedback}

Experience becomes knowledge through reflection, which is enhanced by timely and appropriate criticism. Effective e-learning design will include provision for feedback that amplifies the learning from the experience, and enables students to increase their level of skill and knowledge. The range of available feedback strategies is vast, including reflective responses to prescribed questions, semi-automated responses by the system to student actions and work, shared comments in online forums and blogs, and personal responses via email, telephone, and post. The technologically mediated nature of e-learning is perhaps most apparent in the element of feedback, and the challenges are significant for e-learning in domains that have traditionally relied heavily on interpersonal communication, in particular, psychological counseling and the performing arts where "one-to-one is the traditional norm" (Green, 2002, p. 128). Timeliness of feedback is also a consideration. Timeliness may be enhanced through automation in some cases, or it might be delayed, such as where email responses replace tutorial question and answer sessions. Effective use of feedback will enable an e-learning design to set up a dialogue within which the student participates, without which designs may simply become plans for broadcasting content.

In the TLF learning object Sonic Space City, where students create a soundscape to visual stimulus, feedback mechanisms include the ability to monitor work in progress in real time, and the facility to analyze and enhance projects by recording and replaying audio. In addition, students can describe their finished soundscape according to whether they consider it peaceful or 
noisy, calm or busy, scary or safe. These descriptions may be printed and the views of other class members sought. In this design, deliberate attention has been paid to incorporating multiple avenues for feedback to the learner, both during and after the activity. Students who use this learning object have displayed high levels of motivation and engagement because of the immediate and rich feedback provided by the activity. Activities such as this might be enhanced by enabling feedback from a broader range of people via the presentation of their soundscapes in an online forum, where reviews and downloads could provide qualitative and quantitative feedback about the appeal of their musical creation to others.

\section{Delivery}

Good educational design relies on appropriate delivery to reach its full potential. Conditions for defining appropriate or effective delivery are not easily specified because of contextual variations on learning environments, and in this article we do not attempt to define any particular means of effective delivery. We do, however, provide some guidelines for the delivery of e-learning that relate to the elements of activity, scenario, and feedback. There is often a design tension between the practicalities of electronic production or delivery on the one hand (such as data transfer rates, file size, security, and cost) and the requirements of the learning activities on the other (for example, timely interaction, rich media content, and a desire for social communication and communal distribution). The appropriate delivery of e-learning should aim to maximize the engagement of the student with the activity, enable the communication of stimulating contexts, and maximize opportunities for feedback and reflection. At times, this may stretch the technical boundaries of e-learning systems, which presents an opportunity for new solutions and technologies, but, at other times, it may mean that simpler delivery strategies are most appropriate, perhaps even ones that are not electronic. As part of the design of the TLF learning resource Campaign Manager, where a student takes on the role of coordinating the activities of a candidate in an election for school captain, the issue of calculating election results was considered. A significant advantage of using electronic media in the delivery of this learning activity was that an interesting model of voting preferences (based on real student surveys) could be used to provide a dynamic situation where outcomes varied each time that the activity was undertaken, based both on user choices and on the 'random' choices made by computercontrolled opposition candidates. The use of dynamic simulation enabled by computer delivery offered a significant advantage over more static delivery options, such as paper and video.

\section{Context}

The situation within which the e-learning resources are to be used has a significant influence on the design, but may only be partially predictable. Some aspects of the usage context are implied by the elements previously described; however, the broader context is also relevant to addressing learning needs (Siemens, 2003). Elements of activity, scenario, and feedback need to take into account the users' profiles and the delivery element needs to consider the technical infrastructure. However, additional contextual considerations include the institutional objectives of the elearning program, the role and skills of any instructor, longevity of the resources, and cultural sensitivities. The connection between context and delivery methods is highlighted by Silverman 
and Casazza (2000), who note that "different systems of communication seem to be at the heart of many of the cultural and ethnic differences that affect the learning environment” (p. 42). Bearing this in mind, it is clear that the broader context within which the learning activity is delivered can influence many elements of e-learning design. One example of the broader context is the supervisory situation that might be assumed. One of the key criteria that inform the design of TLF materials, for example, is that the materials should be suitable for use as a stand alone resource, and not assume a detailed level of teacher input. This situation puts particular pressure on the explanatory clarity of instructional design, as reflected in comments on the TLF learning resource Dynamic Fractions. Muirhead and Haughey (2003) note that for this learning resource "the instructions associated with the control panel are complicated and must be simplified" (p. 63). Another aspect of context is how the activity fits into a sequence of learning, exemplified by Muirhead and Haughey's recommendation that the TLF resource Plant Scan would be used best as an assessment activity, since significant prior learning is required. Taking context into account requires that the designer consider the demands and scaffolding inherent in the learners' environment.

\section{Influence}

The difference that the e-learning materials will make is an important design consideration. The influence of the e-learning design can be assessed from a number of perspectives, including the way that it will affect the learner, the ramifications that it will have for the learning (and broader) community into which it will be implemented, and the environmental influence of its development and use. Considerations about the personal influence of the e-learning design might consider the extent of learning that is likely to take place compared to the effort required to produce the resource. They might also consider the potential effect of the content and its presentation on a person's self-esteem and other psychological states (Raskin, 2000) - in short, the extent to which the content benefits the user. Considerations about the social influence of the e-learning design might include the cultural appropriateness of the material, the extent to which the design makes demands on others working with or supervising the learner, the way that it may influence cultural capital in the educational setting, and the ethical values implicit in the design or content (Brennan, 2003; Ehn, 1992) - in short, the extent to which people other than the learner will benefit. Considerations about the environmental influence of the design include the use of resources required to develop and deliver the e-learning materials, and the influence on the environment of activities required by people using or administering the learning materials - in short, the extent to which the environment will benefit from the design. As Arnold Pacey (1999) concludes, "sensibilities regarding people and nature seem central to what technology ought to be about" (p. 222). Considering the influence of the design requires designers to appreciate their relationship with, and influence upon, the learner and the learner's social and physical context. Designers need to act in a responsible and ethical manner to ensure that the impact of their elearning design is of benefit to the learner, society, and the environment. The TLF employs participatory or cooperative design processes that include conducting workshops that involve expert focus groups. These groups, in addition to educational specialists and designers, are comprised of teachers from a range of Australian states and territories who participate in the quality assurance, evaluation, and review phases of a project by providing in-context user 
feedback about the development process. User participation in design can be particularly important where there are cultural sensitivity issues. The degree of attention to aspects of impact in TLF projects, however, was heavily dependent on the people involved in their development. A TLF project that paid particular attention to influence was Studies of Australia. This project developed digital resources that support the study of Australian history, geography, Indigenous studies, environmental studies, values, and cultural studies, with a focus on the experience of regional and rural Australians.

\section{Conclusion}

The elements of effective design highlighted in this paper stem from a focus on student experience, while taking into account the broader networks that contribute to and are influenced by that experience. We encourage a participatory design and implementation approach, where the e-learning system is a two-way street, allowing early and ongoing communications between designer and users, rather than a conduit directed at the learner or educator. We assert that the practicalities of design methodologies should elaborate on the elements presented in this paper. In compiling these elements of effective design, we were aware that technology affords opportunities to educational designers to amplify the strengths and weaknesses in both the activities and the delivery systems. It is because of this amplification of technological tendencies that the design phase is so critical. These six elements - activity, scenario, feedback, delivery, context, and influence - provide foci for the educational designer, assisting in the navigation of the complexities and the often contradictory pressures that influence the development of an effective e-learning design. 


\section{References}

Bersin, J. (2003). What works in blended learning. Learning Circuits, July. Retrieved October 19, 2003 from: http://www.learningcircuits.org/2003/jul2003/bersin.htm

Biggs, J. B. (1991). Teaching for Learning: The view from cognitive psychology. Hawthorn, Vic: Australian Council for Educational Research.

Brennan, R. (2003). One Size Doesn't Fit All - Pedagogy in the online environment: Vol. 1. Adelaide:

National Centre for Vocational Education Research. Retrieved October 17, 2003 from: http://www.ncver.edu.au/publications/965.html

Brodsky, M. (2003). E-learning Trends, Today and Beyond. Learning and Training Innovations, May. Retrieved October 17, 2003 from: http://www.elearningmag.com/ltimagazine/article/articleDetail.jsp?id=56219

Dewey, J. (1970). Experience and education. New York: Collier Books.

Ehn, P. (1992). Scandinavian Design: On participation and skill. In P. S. Adler and T. A. Winograd (Eds.) Usability: Turning technologies into tools (p. 96-132). New York: Oxford University Press.

Frydenberg, J. (2002). Quality standards in e-learning: A matrix of analysis. International Review of Research in Open and Distance Learning, 3(2). Retrieved October 17, 2003 from: http://www.irrodl.org/content/v3.2/frydenberg.html

Gee, J. P. (2003). What video games have to teach us about learning and literacy. New York: Palgrave Macmillan.

Green, L. (2002). How Popular Musicians Learn: A way ahead for music education. Aldershot, UK and Burlington, VT.: Ashgate.

Horton, S. (2000). Web Teaching Guide: A practical approach to creating course web sites. New Haven, CT.: Yale University Press.

Jasinski, M. (2001). E-Games: Improvisation through open platform design. Paper presented at the Moving Online conference. September 2-4. Gold Coast, Qld.

Muirhead, B., and Haughey, M. (2003). An assessment of the learning objects, models and frameworks developed by the Learning Federation Schools Online Curriculum Content Initiative. Retrieved February 11, 2004 from: 
http://www.thelearningfederation.edu.au/tlf/newcms/view_page.asp?page_id= 8620\&Men_Id=4

Nash, S. S. (2004). How the mind makes meaning in e-learning (Part 1). Xplanazine, June. Retrieved October 17, 2004 from: http://www.xplanazine.com/archives/2004/06/how the mind ma 1.php

Pacey, A. (1999). Meaning in Technology. Cambridge, MA.: The MIT Press.

Raskin, J. (2000). The Humane Interface: New directions in designing interactive systems. Reading, MA.: Addison Wesley.

Shakar, M., and Neumann, Y. (2003). Differences Between Traditional and Distance Education Academic Performances: A meta-analytic approach. International Review of Research in Open and Distance Learning, 4(2). Retrieved October 17, 2004 from: http://www.irrodl.org/content/v4.2/shachar-neumann.html

Siemens, G. (2003). Learning Ecology, Communities and Networks: Extending the classroom. elearnspace,

October Retrieved October17, 2004, from: http://www.elearnspace.org/Articles/learning_communities.htm

Silverman, S. L., and Casazza, M. E. (2000). Learning and Development: Making connections to enhance teaching. San Francisco: Jossey-Bass.

Young, L. (2003). Bridging Theory and Practice: Developing guidelines to facilitate the design of computer-based learning environments. Canadian Journal of Learning and Technology, 23(3). Retrieved October 17, 2004 from: http://www.cjlt.ca/content/vol29.3/cjlt293_art4.html

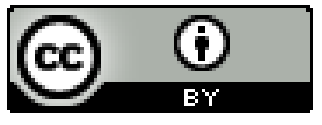

